\title{
EL CONCEPTO DE SERVICIO PÚBLICO A LA LUZ DEL DERECHO COMUNITARIO
}

\author{
JoAQuín TORNOS MAS \\ Catedrático de Derecho Administrativo \\ Universidad de Barcelona
}

\begin{abstract}
RESUMEN
Se examina en este artículo el concepto de servicio público según la doctrina y jurisprudencia española y su conexión con el derecho comunitario.

Mientras en el sistema español se ha impuesto un concepto estricto de carácter subjetivo, al que se añaden los servicios públicos personales en régimen de concurrencia, el derecho comunitario ha impuesto un proceso de liberalización de los servicios públicos económicos, compatible con el reconocimiento de algunas excepciones a las reglas de la concurrencia en los servicios de interés económico general. Posteriormente el derecho comunitario ha reconocido la existencia de servicios de interés general como elementos necesarios para la cohesión social y económica.

El trabajo pone en conexión las construcciones dogmáticas españolas con los conceptos comunitarios de Servicios de Interés General, (SIG), Servicios de Interés Económico General (SIEG), y Servicios de Interés General No Económicos (SIGNE).
\end{abstract}

Palabras clave: publicatio; servicios de interés general; servicios de interés económico general; servicios de interés general no económicos; servicio público.

\begin{abstract}
This article analyzes the concept of public service from the point of view of the Spanish academia and jurisprudence as well as its connection to EU law. In the Spanish national system a strict concept of subjective nature has been established that enters into competition with personal public services. On the contrary, EU law has opted for the liberalization of economic public services that is compatible with the recognition of exceptions to the competition rules regarding services of general economic interest. The EU has also recognized these services of general economic interest as necessary elements to achieve social and economic cohesion.

This work links the stances of the Spanish academia and jurisprudence with the concepts of Service of General Interest (SGI), Service of General Economic Interest (SGEI) and Non-economic Service of General Interest (NESGI) fostered at EU level.
\end{abstract}

Key words: publication; services of general interest; services of general economic interest; non economic services of general interest; public services. 


\section{SUMARIO}

I. INTRODUCCIÓN.-II. El CONCEPTO DE SERVICIO PÚBLICO EN EL DERECHO ESPAÑOL.III. El impacto del DERECHO EURopeo. SERVICIOS DE INTERÉS GENERAL, SERVICIOS DE INTERÉS ECONÓMICO GENERAL Y SERVICIOS DE INTERÉS GENERAL NO ECONÓMICOS.-IV. LOS CONCEPTOS DE SERVICIO PÚBLICO EN EL DERECHO INTERNO Y EN EL DERECHO EUROPEO.

\section{INTRODUCCIÓN}

El año 1999, en el número 150 de esta misma Revista, el profesor Tomás Ramón Fernández publicó un brillante trabajo titulado «Del servicio público a la liberalización. Desde 1950 hasta hoy». En dicho trabajo se analizaba el contenido del concepto de servicio público como un concepto central dentro del derecho administrativo, siempre en crisis y necesitado de renovación en los últimos años por las aportaciones del derecho comunitario. Para el citado profesor, detrás de la calificación de una actividad como servicio público hay siempre una necesidad generalmente sentida que no puede ser satisfecha individualmente, y a la que debe proveer el Estado para garantizar la necesaria cohesión social. Pero añadía que el concepto jurídico, que ha ido evolucionando con el tiempo, es confuso, y la amplitud con la que se le quiere dotar acaba provocando que «la neblina no permita distinguir los contornos de la figura».

A partir de este planteamiento, trataré de avanzar en la precisión del concepto de servicio público propio de nuestro ordenamiento, poniéndolo de nuevo en conexión con el derecho comunitario, un derecho que ha evolucionado desde la primaria finalidad de la construcción europea a través de un proceso gradual de conformación de un mercado único, a la finalidad complementaria de lograr la cohesión económica y social y la solidaridad entre los Estados miembros. Se han construido de este modo los conceptos de servicios económicos de interés general y servicios de interés general, que nos servirán de referentes para delimitar nuestro concepto más estricto de servicio público y nuestra tradicional distinción entre servicios públicos económicos y servicios personales o sociales.

\section{El CONCEPTO DE SERVICIO PÚBLICO EN EL DERECHO ESPAÑOL}

El origen de la fuerza del concepto de servicio público se debe a la doctrina de Leon Duguit. Para el decano de Burdeos, servicio público es «toda actividad cuyo cumplimiento debe ser regulado, asegurado y 
fiscalizado por los gobernantes, porque el cumplimiento de esa actividad es indispensable para la realización y desenvolvimiento de la interdependencia social y de tal naturaleza que no puede ser asegurada completamente más que por la intervención de la fuerza gobernante». Con esta noción Duguit pretendía legitimar toda la actividad del Estado moderno, un Estado que no podía sustentarse en un concepto abstracto como el de soberanía sino en la garantía de todas las prestaciones necesarias para la vida colectiva.

Surge así un concepto amplio y objetivo de servicio público, que muta en su extensión en tanto debe adecuarse a la realidad socioeconómica de cada momento, y que por su propia amplitud tiene los contornos desfigurados. Este concepto incluye la prestación de servicios por la propia administración, la regulación de actividades privadas de interés general y los servicios de autoridad.

La creciente intervención de la Administración pública después de Weimar y la crisis de 1929 abrirá un nuevo frente por el que hace aparición una nueva acepción del concepto de servicio público. La tradicional separación entre Estado y sociedad, y la inicial prohibición de que la Administración lleve a cabo actividades de contenido económico, se va a ver superada. Existen grandes obras públicas que precisan de la intervención administrativa, o surgen necesidades básicas en el ámbito local que requieren la intervención administrativa. Se configura la idea del Estado prestacional, y con el fin de justificar la presencia en actividades económicas del sector público y excluir de las mismas al sector privado se recurre al concepto de servicio público. Determinadas grandes obras, como la creación de la red ferroviaria o el servicio de telefonía, o la prestación del servicio postal en todo el territorio nacional exigían que estas obras o actividades se prestaran en régimen de monopolio. La presencia de lo público no supone la gestión directa, pero sí la asunción de la titularidad de la actividad, el monopolio de la actividad y la exclusión de la misma del régimen de libre mercado. Sólo con el monopolio público y la exclusión de la libertad en el mercado se podía asegurar la concurrencia de empresas privadas para llevar a cabo las obras o los servicios que se juzgaban imprescindibles para el conjunto de la sociedad. Esta falta de libertad en el mercado es compatible con la libertad por el mercado, es decir, con la concurrencia para acceder a la gestión indirecta de estos servicios.

La presencia pública deja de justificarse en base al título demanial, la propiedad de las vías del tren o de los terrenos de los tendidos telefónicos, para sustentarse en el concepto de servicio público. Las actividades prestacionales de carácter esencial para la vida colectiva que el merca- 
do no garantiza son servicios públicos en virtud de su publicatio, de la asunción de su titularidad por los poderes públicos. Ello no supone monopolio de gestión, ya que se mantiene la libertad por el mercado, pero para la prestación de estos servicios se requiere un título habilitante, generalmente el título concesional. Público y privado colaboran de este modo en la prestación de servicios públicos, es decir, de las actividades de contenido económico que se han sustraído del juego de la libre iniciativa económica.

Esta realidad es igualmente visible en el mundo local. La vida en las ciudades exige garantizar el acceso al agua, gas, electricidad, se deben construir cloacas e instalar el alumbrado público, recoger las basuras y tratarlas y atender a los servicios funerarios. El Estatuto municipal convierte estas actividades en servicios públicos locales, que los municipios deben asumir bajo su responsabilidad a través de la municipalización. Una vez municipalizados, podrán optar entre su gestión directa o indirecta.

De esta forma el concepto de servicio público se vincula a los servicios de contenido económico, muchos de los cuales se deben prestar en red. Por otra parte, los servicios públicos son actividades económicas excluidas de la libre iniciativa económica, lo que obliga a modular el principio de libre iniciativa económica, como libertad de libre acceso a toda actividad. La libertad en el ejercicio de actividades económicas se reconduce a la libertad por el mercado a través de la gestión indirecta y la imposición de procedimientos de concurrencia para acceder a estas prestaciones.

Junto a los servicios públicos se sitúan las actividades económicas fuertemente reglamentadas, algunas de las cuales están directamente vinculadas con fines de interés general, pero sin que sobre las mismas se haya llevado a cabo una publicatio y su exclusión del mercado. Se exigirá en estos casos una autorización para poder llevar a cabo la actividad, incluso puede tratarse de una autorización contingentada, pero no son servicios públicos en la medida en que la actividad se presta en concurrencia. Son los llamados servicios públicos virtuales o impropios, dentro de los cuales podemos identificar la banca privada, las farmacias o los taxis.

Esta construcción conceptual, basada en la idea de monopolio de titularidad y no concurrencia, se ve superada por la existencia de otros servicios públicos que no responden al principio básico de la inexistencia de concurrencia. A lo largo de la segunda mitad del siglo xx en nuestro país la sanidad y la educación se convertirán en servicios públicos, esto es, en actividades prestacionales que la Administración garantiza a 
todos los ciudadanos en condiciones de igualdad y asequibilidad. Ambas prestaciones se califican como servicios públicos, pero las diferencias con los servicios económicos son notables. Estas actividades se venían prestando por el sector privado, y su conversión en servicio público no supone la creación de un monopolio de titularidad, y menos aún de titularidad y gestión. De hecho la libre iniciativa privada va a estar incluso garantizada constitucionalmente, como en el caso de la educación. En estos servicios públicos, a los que pueden añadirse algunos servicios sociales, lo relevante es que la prestación se reconoce como un derecho de los ciudadanos y, por tanto, esta prestación es una obligación que la Administración debe garantizar. Son servicios que por otra parte se reconocen en el texto constitucional y cuyo contenido concreto se determina en las leyes de desarrollo y en las cartas de servicios.

Estos servicios se suelen calificar como servicios personales frente a los anteriores servicios económicos. Con esta expresión - servicios personales- se destaca el hecho de que se prestan en concurrencia, que no implican monopolio de titularidad, pero también se quiere señalar la importancia de quien presta este servicio y la relación directa que se establece con el usuario. Quién es el maestro de nuestros hijos, o qué servicio médico hospitalario nos atiende, es algo que interesa al usuario de estos servicios. No así quien conduce el autobús municipal o lleva a cabo el alumbrado de nuestra calle.

En todo caso en nuestro sistema, tras las diversas aportaciones iniciales de las que nos da cuenta Tomás Ramón Fernández en el trabajo antes citado, el concepto de servicio público se ha construido fundamentalmente sobre la base de la concepción subjetiva.

En efecto, si atendemos a nuestra doctrina, constatamos cómo en los más recientes manuales al uso el concepto de servicio público que se impone es el concepto estricto o de naturaleza subjetiva.

Así, Santamaría Pastor (Principios de derecho administrativo $I, 2^{\mathrm{a}}$ edición, Iustel, Madrid, 2009, pág. 304) nos dice que «desde una perspectiva formal el dato básico es que formalmente el Estado (u otro ente territorial) asume el deber y la responsabilidad de garantizar su prestación, regular y correcta a los ciudadanos, bien realizándola por si o asegurando su realización por tercero; un acto de asunción que suele ser conocido con el nombre de publicatio».

Sánchez Morón (Derecho administrativo. Parte General, $7^{\text {a }}$ edición, ed. Tecnos, Madrid, 2011, pág. 766), por su parte, señala cómo «el rechazo de la concepción omnicomprensiva de la Escuela del Servicio Público ha dado paso, allí donde su influencia permanece, a una segunda noción, más restringida, del servicio público, que lo identifica tan sólo con las ac- 
tividades de titularidad pública que tienen como objeto directo la prestación material de un servicio a los ciudadanos... las notas que caracterizan esta segunda noción de servicio público son por consiguiente la atribución del servicio a la titularidad de una Administración, ya sea en régimen de monopolio o en competencia con la iniciativa privada - como sucede con la enseñanza o la sanidad-y la finalidad prestacional».

Fernández Farreres (Sistema de derecho administrativo, $1^{\mathrm{a}}$ edición, Civitas Thomson Reuters, Cizur Menor, 2012, pág. 420) afirma que «el servicio público ha quedado referido mayoritariamente, al menos en la doctrina española, al conjunto de actividades prestacionales asumidas o reservadas al Estado con el fin de satisfacer necesidades colectivas de interés general, siendo por tanto nota distintiva la publicatio, es decir, la titularidad pública de la actividad en cuestión y la subsiguiente quiebra de la libertad de empresa. Una publicatio que en ocasiones se acompaña de la gestión directa por la propia Administración (produciéndose así el monopolio de gestión)... el servicio público, caracterizado de esta manera, presenta perfiles claramente definidos».

Finalmente, Esteve Pardo (Lecciones de derecho administrativo, $3^{\mathrm{a}}$ edición, Marcial Pons, Madrid, 2013) sostiene que «el sistema tradicional de servicios públicos que acabamos de estudiar tiene como premisa fundamental la exclusión del mercado de estos servicios y su gestión. Son servicios que se reservan al sector público, se sustraen por tanto de la órbita del mercado y la libertad de empresa para situarse bajo la titularidad de una Administración pública».

Con pequeños matices, la idea central es la existencia de una publicatio, de una asunción por parte de un ente público de la titularidad de la actividad prestacional, que luego se podrá prestar de forma directa o indirecta. La publicatio permite excepcionar las reglas del mercado, y habilita al titular del servicio para en su caso contratar con un tercero la gestión indirecta del servicio. Así se recoge en la actualidad en el artículo 132 del TRLCSP: «antes de proceder a la contratación de un servicio público, deberá haberse establecido su régimen jurídico, que declare expresamente que la actividad de que se trata queda asumida por la Administración respectiva como propia de la misma».

La jurisprudencia también ha defendido la tesis subjetiva, si bien de forma menos contundente, reconociendo también la tesis objetiva o la posibilidad de que determinadas actividades sobre las que no existe publicatio puedan ser calificadas como servicios públicos si responden a fines de interés general o son competencia propia de los entes locales.

La tesis subjetiva la encontramos en la Sentencia de 2 de marzo de 1979, RJ 1979/1175, en la que se afirma que: 
[...] como se desprende claramente de la sistemática y contexto del Reglamento de Servicios de las Corporaciones Locales, estas entidades desarrollan una triple actividad de intervención, fomento y servicio público, y esta última puede ser gestionada directamente por la Corporación o prestada mediante concesión, arrendamiento o concierto, mas en todo caso, para que con rigor pueda predicarse de una actividad el carácter de servicio público, no es suficiente que proporcione una utilidad al público, so pena de desnaturalizar el concepto, sino que debe exigirse que se trate de una actuación técnica, dirigida al público, prestada de forma regular y continua, encaminada a la satisfacción de una necesidad pública, y cuya titularidad esté atribuida a una Entidad Pública, lo que no es obstáculo para que la gestión corresponda a un particular, notas todas ellas que sirven para detectar lo que no es un servicio público, sino simplemente un servicio de interés público, expresión que acoge aquellas actividades cuya titularidad no corresponde a una Entidad Pública, sino que, permaneciendo en manos de los particulares, están destinadas al público y en las que hay implicado un interés público capaz de justificar una intervención administrativa por vía de reglamentación policial, actividades, en fin, conocidas con el nombre de servicios públicos impropios, que no son objeto de convenio por alguno de los procedimientos de selección del contratista, sino que están sometidas a la obtención de una autorización administrativa previa, servicios públicos impropios a los que hace referencia el art. 1 núm. 4 del Reglamento de Servicios (que los denomina servicios de particulares destinados al público) y el art. 17 del mismo Cuerpo legal (donde son llamados servicios privados prestados al público), claramente diferentes, pues, de los servicios públicos en sentido estricto, cuya contratación sí debe hacerse siguiendo los cauces establecidos en el Reglamento de Contratación de las Corporaciones Locales presupuesto todo lo anterior, es claro que la simple y elemental actividad de instalar y alquilar la utilización de hamacas, colchones y parasoles, no constituye un servicio público, en sentido técnico, sino, simplemente, una actividad prestada por particulares, de utilidad pública, y por ello, corporativamente intervenida (en sentido similar, la sentencia del Tribunal Supremo de 24 de octubre de 1989, RJ 1989/8390).

Pero existe una línea diversa que niega que el concepto estricto sea el único admisible. En su Sentencia de 6 de mayo de 1999, recurso de casación 2298/1993, el Tribunal Supremo nos dice que

[...] el motivo no puede prosperar, pues el concepto restrictivo de servicio público sobre el que gira su argumentación, coincidente con la acepción especial de servicio público esencial, esto es, de sectores de actividad reservados en principio, con o sin monopolio, a la iniciativa y gestión de la entidad pública (véase el art. 128.2 CE), no se compadece con el concepto legal del artículo 85.1 de la Ley 7/1985, de 2 de abril, Reguladora de las Bases del Régimen Local, según el cual "son servicios públicos locales cuantos tienden 
a la consecución de los fines señalados como de la competencia de las Entidades locales", siendo de destacar la clara conexión que mantiene el servicio de aparcamiento público con la competencia sobre "la ordenación del tráfico de vehículos y personas en las vías urbanas", que el artículo 25.2 b) de la misma Ley atribuye a los municipios; y ello sin olvidar que este mismo precepto describe con carácter general la competencia municipal incluyendo en ella la prestación de "cuantos servicios públicos contribuyan a satisfacer las necesidades y aspiraciones de la comunidad vecinal", no siendo posible desconocer que entre las necesidades actuales de la población urbana figura la de disponer de servicios de aparcamiento público. Y en cuanto a la jurisprudencia, frente a la única sentencia que cita el motivo, alusiva al concepto estricto de servicio público al que antes se ha hecho referencia, es abundante la jurisprudencia que califica específicamente como servicio público municipal la actividad de aparcamiento público prestada por particulares en régimen de concesión sobre terrenos de dominio público, pudiendo citarse en este sentido, además de la Sentencia de 27 de julio de 1983 que cita la recurrida, las de 8 de noviembre de 1990 (RJ 1990\9179) y 11 de marzo y 12 de junio de 1991 (RJ 1991\2048 y RJ 1991\4965), y las en ellas citadas.

También entre otras, la de 22 de septiembre de 1986, RJ 1986/4638. En materia de servicios deportivos se pueden ver las Sentencias de 20 de junio de 2006, recurso de casación 9108/2003 y la de 29 de junio de 2009, recurso de casación 5709/2004.

Lo expuesto nos permite concluir que en nuestro derecho el concepto de servicio público se identifica mayoritariamente con aquellas actividades prestacionales de interés general cuya titularidad ha sido asumida por la Administración (publicatio), para su prestación de acuerdo con los principios de asequibilidad, igualdad, continuidad y calidad. La asunción de la titularidad puede ser con exclusión o no de la libre iniciativa económica (no existe tal exclusión en los servicios personales o de solidaridad, como sanidad y educación). Junto a estos servicios públicos se pueden reconocer los servicios públicos locales que no son objeto de publicatio, sino ejercicio de una competencia local consistente en la prestación de un servicio de interés general (aparcamientos subterráneos, centros deportivos). Ya fuera del concepto de servicio público se situarían las actividades reglamentadas por razones de interés general. En este caso el mercado garantiza en principio la prestación de la actividad, pero el derecho puede alterar las reglas de la competencia otorgando ventajas o imponiendo obligaciones de servicio público para conseguir que los fines de interés general inherentes a estas actividades (muchas de ellas originariamente auténticos servicios públicos subjetivos) puedan cumplirse. 
III. El impacto del derecho Europeo. Servicios de interés general, SERVICIOS DE INTERÉS ECONÓMICO GENERAL Y SERVICIOS DE INTERÉS GENERAL NO ECONÓMICOS

El impacto del derecho comunitario sobre esta construcción dogmática ha sido muy importante. Europa se construye a través de un proceso gradual que tiene como principal y primer objetivo lograr la integración económica creando para ello un mercado común europeo. Por esta razón se impulsa un proceso de liberalización de muchos servicios económicos con la finalidad de crear este mercado único, y se imponen unas reglas comunes en materia de competencia, desde el convencimiento de que el mercado puede garantizar las prestaciones propias de estos servicios públicos, y que la competencia mejorará la calidad y el precio de los servicios. Para el derecho europeo los servicios públicos clásicos son anticompetitivos y por ello antieconómicos. Se impone así la liberalización de la telefonía, televisiones, servicios postales, suministro de gas y electricidad, transportes, correos y algunos servicios locales como los servicios funerarios. Estos servicios se devuelven al mercado. Por el contrario, nada se dice en un primer momento de los servicios personales o de cohesión social, ya que estos no se prestaban en régimen de monopolio, no se identificaban con servicios de contenido económico y no se consideran de la competencia propia de las instituciones comunitarias.

La liberalización, no obstante, no conlleva que estos servicios pierdan su naturaleza de servicios de interés general, pues las prestaciones que realizan a favor de los consumidores o usuarios siguen siendo de interés general. Así, por ejemplo, el que todos los ciudadanos puedan acceder a los servicios de electricidad y gas, o que puedan disponer a su muerte de un entierro digno. Por ello el derecho comunitario construye de forma sucesiva a la liberalización el concepto de servicio económico de interés general, en el que se pueden englobar aquellas actividades económicas de carácter prestacional que poseen un fin de interés general. El derecho se ocupa de abrir el mercado y asegurar la concurrencia, pero no quiere dejar abandonados a los ciudadanos cuando el mercado no garantiza un acceso a los servicios de interés general en condiciones de igualdad y asequibilidad. En estos casos las reglas de competencia pueden modularse, dado que se admiten fallos del mercado. Si los fines de interés general no están garantizados por el funcionamiento de un mercado regulado por las reglas de libre concurrencia, se podrán establecer excepciones que, eso sí, tengan como único fin el garantizar estos fines de interés general. 
Este es el sentido del anterior artículo 86 del Tratado de la Comunidad Europea y actual artículo 106 del TFUE: «Las empresas encargadas de la gestión de servicios de interés económico general o que tengan el carácter de monopolio fiscal quedarán sometidas a las normas de los Tratados, en especial a las normas sobre competencia, en la medida en que la aplicación de dichas normas no impida, de hecho o de derecho, el cumplimiento de la misión específica a ella confiada». El precepto permite excepcionar las normas sobre competencia si ello es necesario para que las empresas liberalizadas puedan seguir cumpliendo con unos fines de interés general que siguen siendo inherentes a su actividad, y que los poderes públicos no pueden desconocer. Del mismo modo, el artículo 14 del TFUE (artículo 16 en el Tratado de Amsterdam), situado dentro de las disposiciones generales del Tratado, dispone que «sin perjuicio del artículo 4 del Tratado de la Unión Europea y de los artículos 93, 106 y 107 del presente Tratado, y a la vista del lugar que los servicios de interés económico general ocupan entre los valores comunes de la Unión, así como de su papel en la promoción de la cohesión social y territorial, la Unión y los Estados miembros, con arreglo a sus competencias respectivas y en el ámbito de aplicación de los Tratados, velarán por que dichos servicios actúen con arreglo a principios y condiciones, en particular económicas y financieras, que les permitan cumplir su cometido. El Parlamento Europeo y el Consejo establecerán dichos principios y condiciones mediante reglamentos, con arreglo al procedimiento legislativo ordinario, sin perjuicio de la competencia que incumbe a los Estados miembros, dentro del respeto a los Tratados, para prestar, encargar y financiar dichos servicios».

De este modo, aunque sin definirlo, se introduce el concepto de servicio económico de interés general, con el que de hecho se quieren identificar aquellas actividades de contenido económico que han sido objeto de procesos de liberalización, y que por tanto deben llevarse a cabo de acuerdo con los principios de la competencia, si bien estos principios podrán excepcionarse si ello es imprescindible para que se puedan alcanzar los fines de interés general inherentes a estas actividades y que las reglas del mercado no garantizan. La figura de los SIEG permite que la liberalización se lleve a cabo de forma controlada y sin merma de los fines de interés general propios de estas actividades, antes servicios públicos en régimen de monopolio. La definición seguramente más precisa de los SIEG la encontramos en la «Comunicación sobre los servicios de interés general en Europa» de la Comisión de diciembre de 2000, donde se afirma que este concepto: "es el término utilizado en el artículo 86 del Tratado - hoy artículo 106- y se refiere a los servicios de mercado 
a los que los Estados miembros imponen determinadas obligaciones de servicio público en virtud de criterios de interés general». Más recientemente la Directiva de Servicios 123/2006 ha vuelto a ocuparse de los SIEG, estableciendo en su considerando 70 que «sólo pueden considerarse servicios de interés económico general si se prestan en ejecución de una tarea especial de interés público confiada al prestador por el Estado miembro en cuestión».

Las excepciones pueden ser unos regímenes de ayudas públicas que alteren las reglas de la competencia, o la imposición de obligaciones de servicio público o de servicio universal. Las primeras obligaciones más vinculadas al logro de finalidades como la eficiencia o la seguridad en la prestación de los servicios, y las segundas más focalizadas en el logro de fines de cohesión social y territorial. Así, por ejemplo, las empresas liberalizadas que actúan en el mercado energético se pueden ver obligadas a garantizar el acceso al suministro eléctrico a las personas en situaciones de pobreza energética. La Directiva 2009/72/CE establece en su expositivo 50 lo siguiente: «Deben reforzarse las obligaciones de servicio público, inclusive en materia de servicio universal, y las consiguientes normas mínimas comunes para asegurarse de que todos los consumidores, en particular los vulnerables, puedan beneficiarse de la competencia y de precios justos. Los requisitos de servicio público en el ámbito nacional deben definirse teniendo en cuenta las circunstancias nacionales, en el respeto, no obstante, del derecho comunitario por los Estados miembros. Los ciudadanos de la Unión y, cuando los Estados miembros lo estimen adecuado, las pequeñas empresas deben poder beneficiarse de las obligaciones de servicio público, en particular con respecto a la 06/112L SE seguridad del suministro y unos precios razonables».

Las ayudas públicas admitidas pueden estar directamente vinculadas al logro de las finalidades de servicio público que se impongan a las empresas liberalizadas. Así se expone en la Decisión del órgano de vigilancia de la AELC de 25 de enero de 2012 (DOUE núm. 161 de 13 de junio de 2013) por la que se modifican las normas sustantivas y de procedimiento en el ámbito de las ayudas estatales, cuyo objetivo es precisar los requisitos de las ayudas estatales más relevantes para la compensación por servicio público.

La existencia de obligaciones de servicio público se convierten de este modo en el elemento determinante para admitir la concesión de ayudas públicas estatales y para justificar introducir excepciones al régimen de libre competencia. Un caso económicamente poco relevante, en relación por otra parte a una actividad económica con poco predica- 
mento entre nosotros, puede servirnos de ejemplo de esta justificación de la admisión de excepciones a las reglas del mercado.

El TJUE, al resolver una cuestión prejudicial, tuvo ocasión de examinar si la actividad de deshollinador podía o no calificarse como SIEG, ya que de ello dependía la admisión o no de unas medidas de contingentación establecidas en un Land austríaco respecto de esta actividad. El conflicto que está en la base de la cuestión prejudicial enfrentaba a un deshollinador austríaco al que no se permitía ejercer esta actividad en el Land de Carintia, ya que en este Land esta actividad estaba territorialmente distribuida entre los sujetos autorizados. En la Sentencia de 23 de diciembre de 2015, Asunto C-293/14, el Tribunal europeo dijo que:

[...] «a este respecto, ciertamente debe señalarse que, como se deduce de los autos en poder del Tribunal de Justicia, los deshollinadores del Land de Carintia desempeñan las actividades del ámbito de la «policía de incendios», con arreglo al considerando 70 de la Directiva 2006/123 y a la jurisprudencia del Tribunal de Justicia, para ejercer una misión particular de servicio público que se les ha confiado mediante una autorización, es decir, su licencia profesional, y en virtud de una norma reglamentaria, a saber, el artículo 26 del Reglamento de policía, que define de manera clara y transparente la naturaleza exacta de la obligación de servicio público encomendada (véanse, por analogía, las sentencias Fallimento Traghetti del Mediterraneo [TJCE 2010, 172], C-140/09, EU:C:2010:335, apartado 37, y Femarbel [TJCE 2013, 214] , C-57/12, EU:C:2013:517, apartado 48). 42.Además, también se desprende de los mencionados autos que, con arreglo al artículo 14 TFUE y al artículo 1 del protocolo (núm. 26) sobre los servicios de interés general, anexo al Tratado FUE, y a reiterada jurisprudencia del Tribunal de Justicia, los deshollinadores registrados en el Land de Carintia están obligados a garantizar, en virtud de la mencionada obligación de servicio público, las misiones incluidas en la "policía de incendios» en beneficio de todos los usuarios del sector que se les ha encomendado de manera que se garantice la igualdad de acceso a las prestaciones, aplicando tarifas uniformes cuyo importe máximo lo fija el presidente de dicho Land (véanse, por analogía, las sentencias Fallimento Traghetti del Mediterráneo [TJCE 2010, 172], C-140/09, EU:C:2010:335, apartado 38, y Femarbel [TJCE 2013, 214], C-57/12, EU:C:2013:517, apartado 47), y garantizando condiciones de calidad similares, sin tener en cuenta situaciones particulares ni el nivel de rentabilidad económica de cada operación individual (véase, en este sentido, la sentencia Corbeau [TJCE 1993, 71], C-320/91, EU:C:1993:198, apartado 15).

El supuesto ilustra claramente la importancia y contenido de las obligaciones de servicio público. 
Pero el derecho de la Unión Europea no se limita a la creación de un mercado único, a liberalizar servicios para introducir la concurrencia y permitir de forma excepcional algunas reglas que rompan la libre competencia en defensa de fines de interés general. Europa también es un espacio de libertad, seguridad y justicia, que tiene como finalidad promover la paz, sus valores y el bienestar de sus pueblos. Como establece el artículo 2 del Tratado de la Unión Europea, «la Unión se fundamenta en los valores de respeto de la dignidad humana, libertad, democracia, igualdad, Estado de derecho y respeto de los derechos humanos, incluidos los derechos de las personas pertenecientes a minorías. Estos valores son comunes a los Estados miembros en una sociedad caracterizada por el pluralismo, la no discriminación, la tolerancia, la justicia, la solidaridad y la igualdad entre mujeres y hombres».

La Unión Europea trata de este modo de cimentar la creación de un pueblo europeo unido por unos valores comunes, y ello lleva directamente a la necesidad de crear unos derechos fundamentales comunes. La Carta de los Derechos Fundamentales de la Unión Europea en su preámbulo nos dice que «consciente de su patrimonio espiritual y moral, la Unión está fundada sobre los valores indivisibles y universales de la dignidad humana, la libertad, la igualdad y la solidaridad, y se basa en los principios de la democracia y del Estado de derecho. Al instituir la ciudadanía de la Unión y crear un espacio de libertad, seguridad y justicia, sitúa a la persona en el centro de su actuación». Carta que entre otros derechos de libertad reconoce los derechos a la educación y a la salud, y el acceso a los servicios económicos de interés general. Aquí nos reaparece Duguit.

Pero lo cierto es que en la actualidad Europa busca su cohesión interna más en los valores de libertad y seguridad que en los vinculados a la prestación de servicios públicos, ya que esta prestación sigue en manos de los Estados miembros. Si Duguit vio en la prestación de los servicios públicos el fundamento de los Estados modernos, lo cierto es que Europa carece no sólo de soberanía sino también de este poder de vertebrar la unión de su ciudadanía a través de la garantía de los servicios públicos. No obstante, la voluntad de hacer de Europa un espacio de libertad y el interés por llegar a hacer realidad la existencia de una ciudadanía europea han hecho patente la preocupación por alcanzar unos niveles de prestación de servicios personales homogéneos dentro de Europa. Es este planteamiento el que creemos ha llevado a crear la categoría más amplia de servicios de interés general, SIG, dentro de la cual pueden ubicarse los servicios económicos de interés general, SIEG.

Como afirmó la Comunicación de la Comisión sobre los servicios de interés general en Europa, de diciembre de 2000 (DO C17 de 19 de enero 
de 2001), los Servicios de Interés General, (SIG), «abarcan los servicios de mercado y no de mercado que las autoridades públicas consideran de interés y a los que imponen determinadas obligaciones de servicio público».

De forma más precisa, el Libro Verde sobre servicios de interés general, COM (2003) 270 final, insiste en que los servicios de interés general son servicios que «las autoridades públicas consideran de interés general y están sometidos a obligaciones específicas de servicio público». A lo que añade que "abarcan un amplio espectro de actividades de diverso tipo - desde actividades propias de las grandes industrias de redes (energía, postales, transporte y telecomunicaciones) hasta la sanidad, la educación y los servicios sociales - de dimensiones diversas, unas de ámbito europeo, incuso mundial, otras de ámbito simplemente local-y de diferente naturaleza, sometidas o no a la disciplina de mercado». En esta misma línea, la Comunicación de la Comisión al Parlamento Europeo, el Consejo, el Comité Económico y Social Europeo y el Comité de las Regiones, COM (2007) 725 final de 20 de noviembre de 2007, afirma que: «Los servicios de interés general abarcan una amplia gama de actividades, que va desde las grandes industrias de red como la energía, las telecomunicaciones, el transporte, la retransmisión audiovisual y los servicios postales, a la educación, el suministro de agua, la gestión de los residuos, la salud y los servicios sociales. Estos servicios son esenciales para la vida cotidiana de los ciudadanos y las empresas, y reflejan el modelo de sociedad europeo. Desempeñan un papel importante en cuanto a asegurar la cohesión social, económica y territorial de toda la Unión y son vitales para el desarrollo sostenible de la UE en términos de mayores niveles de empleo, inclusión social, crecimiento económico y calidad medioambiental» (véanse también el Libro Blanco 2004 COM 374 de 12 de mayo de 2004 sobre los servicios de interés general, y el Dictamen del Parlamento AG-0275/2006 de 26 de septiembre).

Por tanto, junto a los servicios económicos que en principio deben liberalizarse, y que pasarán a ser SIEG, se contemplan ahora otros servicios que no se organizan prioritariamente como actividades económicas y en los que priman los fines de lograr la cohesión social. De este modo, dentro de la categoría general de los SIG, tenemos los SIEG y los SIG$\mathrm{NE}$, es decir, los servicios de interés económico general, y los servicios de interés general no económicos.

$\mathrm{Si}$ en un primer momento la Comisión Económica Europea se preocupó por la liberalización de los servicios públicos estatales en régimen de monopolio, con el fin de hacer realidad la existencia de un mer- 
cado único de servicios, mejorar la eficacia de estas actividades económicas y permitir la creación de grandes compañías europeas de servicios que pudieran competir en un mundo globalizado, y posteriormente se preocupó de corregir las deficiencias del mercado a través de la figura de los SIEG y las obligaciones de servicio público, más tarde reconocerá la importancia de los SIGNE, esto es, los servicios de solidaridad, en tanto constituyen el instrumento para vertebrar la sociedad europea y responden a la ideosincracia de los diferentes Estados que conforman Europa.

Pero en el caso de los SIGNE, servicios de interés general no económicos reconocidos como tales por Europa (sanidad, educación, servicios sociales), no existe, como sí existe en España, una asunción de responsabilidad de la prestación de estos servicios por parte de las instituciones europeas, ya que la competencia sobre estos servicios se reserva a los Estados miembros. Sanidad, educación y servicios sociales son servicios de responsabilidad de los Estados miembros, cuya ordenación no está en principio sujeta a las reglas de la competencia al no tener estos servicios carácter económico (aunque también es cierto que existen servicios sanitarios o sociales que pueden conceptuarse como servicios económicos, en cuyo caso se deberán prestar en concurrencia con el mercado, por lo que no siempre es fácil la distinción entre servicios sociales y económicos).

El distinto alcance competencial de la Unión Europea en el tratamiento de los SIEG y los SIGNE queda perfectamente reflejado en el protocolo núm. 26 al Tratado de Funcionamiento de la Unión Europea:

Artículo 1. Los valores comunes de la Unión con respecto a los servicios de interés económico general con arreglo al artículo 14 del Tratado de Funcionamiento de la Unión Europea incluyen en particular: el papel esencial y la amplia capacidad de discreción de las autoridades nacionales, regionales y locales para prestar, encargar y organizar servicios de interés económico general lo más cercanos posible a las necesidades de los usuarios; la diversidad de los servicios de interés económico general y la disparidad de las necesidades y preferencias de los usuarios que pueden resultar de las diferentes situaciones geográficas, sociales y culturales; un alto nivel de calidad, seguridad y accesibilidad económica, la igualdad de trato y la promoción del acceso universal y de los derechos de los usuarios. Artículo 2. Las disposiciones de los Tratados no afectarán en modo alguno a la competencia de los Estados miembros para prestar, encargar y organizar servicios de interés general que no sean económicos.

Mientras la Unión Europea reivindica la imposición de los valores comunes de la Unión en el tratamiento de los SIEG, aun reconociendo la 
existencia de ámbitos de decisión propios de los Estados miembros para su organización, en el caso de los SIGNE se afirma que las disposiciones de los Tratados, de forma principal las reglas sobre la competencia, no afectarán en modo alguno a las competencias de los Estados miembros. Al no ser servicios de mercado, las normas comunitarias, que regulan servicios económicos pero no servicios de solidaridad y no económicos, no son de aplicación.

En este sentido se puede señalar que cuando el TFUE regula el derecho europeo en materia de salud (artículo 168), de hecho se ocupa de la ordenación en materia de salud pública, pero no regula la asistencia sanitaria, de conformidad con el citado artículo 2 del protocolo 26 y su referencia al principio de subsidiariedad. Ni el derecho europeo se refiere al contenido del derecho a la asistencia sanitaria, y menos aún la Unión Europea organiza la prestación de este servicio. En sentido parecido, el artículo 35 de la Carta de los Derechos Fundamentales de la UE establece que «toda persona tiene derecho a acceder a la prevención sanitaria y a beneficiarse de la atención sanitaria en las condiciones establecidas por las legislaciones y prácticas nacionales». Por tanto, por lo que se refiere a la asistencia sanitaria, estamos ante un SIGNE del que el derecho comunitario no se ocupa.

El exacto alcance y la distinción entre las figuras de SIEG y SIGNE presentan algunos problemas de importancia. Así, en primer lugar, se plantea la cuestión de si la calificación de un servicio de mercado como servicio de interés económico general es una decisión que corresponde o no a los Estados miembros y si estos poseen plena libertad para adoptar esta decisión. El tema es importante, ya que si el servicio de mercado se califica de interés general, podrán justificarse las excepciones a las reglas de la competencia (artículo 106 TFUE), es decir, se podrán imponer obligaciones de servicio público, y se podrán reconocer ventajas para poder llevar a cabo estas obligaciones.

La jurisprudencia comunitaria y diversos informes de las instituciones europeas han reconocido una amplia discrecionalidad a los Estados miembros para determinar cuándo existen fines de interés general vinculados a una determinada prestación, así como para determinar cuándo el mercado no puede garantizar el cumplimiento de estas finalidades. Pero esta decisión no supone que los Estados tengan una absoluta libertad. Así, en la Comunicación de la Comisión UE C 8/02 se afirma, en relación a la existencia de los SIEG:

46. Al no existir unas normas de la Unión que definan el alcance de la existencia de un SIEG, los Estados miembros disponen de un amplio margen 
de apreciación a la hora de definir un determinado servicio como SIEG y de conceder una compensación al proveedor del servicio. Las competencias de la Comisión al respecto se limitan a comprobar si el Estado miembro ha incurrido en error manifiesto al definir el servicio como servicio de interés económico general y al evaluar la ayuda estatal contenida en la compensación. Cuando existan normas específicas de la Unión, el margen de apreciación de los Estados miembros está aún más vinculado a esas normas, sin perjuicio del deber de la Comisión de realizar una evaluación sobre si el SIEG ha sido definido correctamente a efectos del control de las ayudas estatales. 47. El primer criterio Altmark exige la definición de una misión de SIEG. Este requisito coincide con el establecido en el artículo 106, apartado 2 del Tratado. Del artículo 106, apartado 2, del Tratado se desprende que las empresas encargadas de la gestión de SIEG son empresas a las que se ha encomendado «una misión específica». En términos generales, el encargo de una "misión específica de servicio público» implica la prestación de servicios que una empresa, si considerase exclusivamente su propio interés comercial, no asumiría o no asumiría en la misma medida o en las mismas condiciones. Aplicando un criterio de interés general, los Estados miembros o la Unión pueden vincular obligaciones específicas a dichos servicios. 48. Por tanto, la Comisión considera que no sería adecuado vincular obligaciones específicas de servicio público a una actividad que ya efectúan, o pueden efectuar satisfactoriamente y en condiciones, tales como el precio, las características de calidad objetivas, la continuidad y el acceso al servicio acordes con el interés público, definido por el Estado, empresas que operan en condiciones normales de mercado (11). En cuanto a si un servicio puede ser prestado por el mercado, la evaluación de la Comisión se limita a comprobar si el Estado miembro ha cometido un error manifiesto.

Por otro lado, la distinción entre un SIEG y un SIGNE no siempre es clara, y las consecuencias que se derivan de esta distinción son igualmente importantes. Los SIGNE están totalmente excluidos de las reglas de la competencia. Pero ¿todos los servicios sanitarios o servicios sociales son SIGNE? ¿No pueden ser actividades de mercado, a las que pueden querer concurrir en condiciones de competencia empresas privadas? Así, por ejemplo, si en principio los servicios de asistencia sanitaria son SIGNE, el traslado de enfermos mediante ambulancia es un SIEG (STJCE de 28 de octubre de 2001, C-475/199, Glöckner). La Comunicación de la Comisión al Parlamento Europeo, el Consejo, el Comité Económico y Social Europeo y el Comité de las Regiones, COM (2007) 725 final de 20 de noviembre de 2007, trata de fijar criterios de distinción en particular en relación a los servicios sociales y sanitarios. 


\section{LOS CONCEPTOS DE SERVICIO PÚBLICO EN EL DERECHO INTERNO Y EN EL DERECHO EUROPEO}

Llegados a este punto, creemos de interés volver sobre nuestro concepto de servicio público y ponerlo en conexión con los conceptos comunitarios de SIG, SIEG Y SIGNE, con el fin último de precisar el uso respectivo de los diversos conceptos.

Nuestro concepto subjetivo de servicio público, como actividad de titularidad pública excluida del mercado, de hecho no existe en el derecho comunitario. El derecho comunitario impulsa la liberalización de todas las actividades de servicios de contenido económico, y tan sólo contempla estas actividades ya liberalizadas cuando son servicios de interés general. En este sentido se pudo afirmar que el servicio público había muerto. Pero la realidad es que los Estados miembros pueden seguir manteniendo la existencia de servicios públicos subjetivos si las normas comunitarias no han impuesto expresamente su liberalización. Por otra parte, en el ámbito local, menos influido por el derecho comunitario, subsisten auténticos servicios públicos subjetivos, de conformidad con el artículo 86 de la LBRL. Por tanto, nuestro concepto de servicio público económico de carácter subjetivo subsiste al margen del derecho comunitario. También se sitúan fuera del marco comunitario los servicios públicos locales de carácter económico que se prestan en concurrencia, pero que se consideran verdaderos servicios públicos, y como tales excluidos de las reglas de la competencia. Sería el caso de los aparcamientos subterráneos o centros deportivos.

Por otro lado, nuestros servicios públicos personales, o no económicos o de solidaridad (sanidad, educación, servicios sociales), que siempre se han prestado en régimen de concurrencia, pueden equipararse a los SIGNE del derecho comunitario. Como vimos, en este caso la normativa comunitaria aplica el principio de subsidiariedad en toda su extensión y remite la creación y régimen de estos servicios al derecho interno. Recordemos el Protocolo 26 del Tratado de Lisboa, que declara que los Tratados «no afectarán en modo alguno a la competencia de los Estados miembros para prestar, encargar y organizar servicios de interés general que no tengan carácter económico». Tan sólo se reconoce su importancia para una Europa social y cohesionada, pero no se interfiere en su creación y regulación. Europa no asume la responsabilidad de la garantía de estos servicios, como sí lo hacen los poderes públicos españoles respecto de estos servicios en razón de sus respectivas competencias, ya sea por directo mandato constitucional o legal. La única preocupación del derecho comunitario es delimitar cuándo realmente 
estos servicios no suponen ejercicio de actividad económica, ya que en el caso de que sí supongan ejercicio de una actividad de mercado se deberán someter a las reglas de la competencia, aunque puedan tener excepciones. Es decir, pasan a la categoría de SIEG. Pero en principio podemos seguir con nuestro concepto de servicios personales o no económicos y su régimen jurídico.

Cuando se trate de antiguos servicios públicos liberalizados (telecomunicaciones, energía, servicios postales...) deberemos acudir a la figura jurídica de los SIEG, y aplicar en relación a los mismos lo dispuesto en el artículo 106 del TFUE y toda la normativa y jurisprudencia en materia de obligaciones de servicio público y ayudas de Estado. Esta categoría no tiene un concepto equivalente en el derecho español. El derecho comunitario, de hecho, se ocupa exclusivamente de los SIEG liberalizados. El derecho europeo y la jurisprudencia europea se ocupan de fijar el marco de actuación a los nuevos SIEG, no de las formas de gestión de los servicios públicos.

Por último, la categoría de los SIG no es tampoco trasladable de forma automática al derecho español. Bajo esta denominación el derecho europeo incluye los SIEG y los SIGNE, por lo que se trata del modelo conceptual comunitario que como ya hemos visto no es directamente trasladable al modelo conceptual del derecho español. 
